\title{
Improving colorectal cancer screening rates in patients referred to a gastroenterology clinic
}

Bick, Benjamin L.; El-Halabi, Mustapha; Jones, Keaton R.; Kahi, Charles J.; Fayad, Nabil F.

\begin{abstract}
Colorectal cancer $(\mathrm{CRC})$ is the third most common cancer and the second leading cause of cancer related death in the United States. Colonoscopy and fecal immunochemistry testing are the primary recommended $\mathrm{CRC}$ screening modalities. The purpose of this study is to improve rates of CRC screening in Veterans and County hospital patients referred to gastroenterology fellow's clinics. A total of 717 patients between the ages of 49 and 75 (mean $62.0 \pm 6.5$ ) were seen. Prior CRC screening was not done in 109 (15.2\%) due to not being offered (73.4\%) or declining (26.6\%) screening. Patients who received prior CRC screening compared to no prior screening were older (mean age $62.3 \pm 6.4$ vs $60.3 \pm 6.8, \mathrm{p}=0.003)$, white race $(88.6 \%$ vs $78.3 \%$, $\mathrm{p}=0.027)$, and more likely to be Veterans patients $(90.8 \%$ vs $77.5 \%, \mathrm{p}<0.001)$. After systematically discussing options for screening with 78 of the 109 unscreened patients, 56 of them (71.8\%) underwent screening with either colonoscopy (32) or FIT (24). Patients seen by fellows in their last year of training agreed to undergo screening more often than those seen by other fellows $(100 \%$ vs $66.2 \%, \mathrm{p}=0.033)$. Systematic discussions about both colonoscopy and FIT can improve overall rates of CRC screening.
\end{abstract}

Key words: colorectal cancer screening; colonoscopy; fecal immunochemistry testing

This is the author's manuscript of the article published in final edited form as:

Bick, B. L., El-Halabi, M., Jones, K. R., Kahi, C. J., \& Fayad, N. F. (2019). Improving Colorectal Cancer Screening Rates in Patients Referred to a Gastroenterology Clinic. Journal for Healthcare Quality: Official Publication of the National Association for Healthcare Quality, 41(4), 243-250. https://doi.org/10.1097/JHQ.0000000000000170 


\section{INTRODUCTION}

Colorectal cancer $(\mathrm{CRC})$ is the third most common cancer and the second leading cause of cancer related death in the United States. ${ }^{1,2}$ Colonoscopy is considered a cancer prevention test and is the most common CRC screening method used in the United States. It has been shown to decrease CRC incidence and CRC related mortality. ${ }^{3,4}$ Fecal immunochemical tests (FIT) is a sensitive and specific stool based test that detects human globin as a surrogate for advanced colorectal adenomas or cancer. ${ }^{5}$ Guidelines recommend that colonoscopy be performed as the preferred CRC prevention test due to its advantage of providing direct visualization of the colon while allowing endoscopists to perform polypectomy at the time of the exam, but annual FIT is considered a second preferred CRC detection test that provides patients with a non-invasive alternative. ${ }^{6,7}$ Despite the clear evidence that CRC screening is beneficial, its effectiveness is limited by underuse. ${ }^{8}$ Anecdotal experience suggests that patients older than 50 years of age referred to gastroenterologists are not always screened for CRC.

Studies have shown that physicians feel more comfortable recommending colonoscopy over FIT as a CRC screening modality to their patients. ${ }^{9}$ Therefore, higher rates of patients undergoing colonoscopy compared to FIT might be a reflection of physician preference, not patient preference. Patient preference between colonoscopy and FIT is currently unknown.

The primary aim of this study was to improve CRC screening in patients referred to gastroenterology (GI) fellow's clinics. Additional aims included an assessment of patient preference between the primary recommended CRC screening modalities (colonoscopy or FIT) when GI fellows use a standardized approach to discuss CRC screening. 


\section{METHODS}

This is a prospective quality improvement study from October 2016 to February 2017. The main goal of this study was to improve CRC screening rates in average risk patients referred to GI fellows' clinics located either at a local county hospital or a Veterans Administration Medical Center. Additional chart review and data collection was done retrospectively. As a quality improvement project, this study qualified for an IRB waiver.

The study population included all patients aged 49 to 75 years old at the time of the clinic encounter who are considered average risk for CRC. Determination was made as to whether the patient had undergone prior CRC screening either by colonoscopy within 10 years or FIT within 1 year of the clinic encounter. Exclusion criteria included patients at increased risk for CRC due to a family history of CRC and patients with a personal history of neoplastic polyps or CRC. Additionally, if patients required a colonoscopy for other diagnostic purposes as determined at the time of the clinic encounter, they were excluded. To minimize referral bias in patients who had symptoms suggestive of a colonic disorder, the included patients were seen for reasons unrelated to the colon, such as upper GI tract disease, liver disease, and pancreaticobiliary disease.

Fellows conducted a standardized discussion with eligible patients, using a discussion guide and patient provided handout (Supplemental data, Appendix) to allow a consistent approach with all patients; the discussion included an explanation about both screening modalities and the importance of patient preference as to the preferred test. After a decision was made about CRC screening, the fellow then ordered the patient's preferred test. If the patient continued to decline screening, note of this was made in the chart. Co-fellows were then assigned to review each 
other's charts and collect data retrospectively, including patient demographics, inclusion/exclusion criteria, history of prior CRC screening, reasons for declining CRC screening, and choice of screening modality. Data collection was done over 3 separate interim reviews each spanning 5 weeks, to ensure adherence to the quality improvement intervention and to provide feedback for improvement.

Data analysis was performed using Statistical Package for Social Sciences (SPSS) version 21 software (SPSS Inc., Chicago, IL, United States). Continuous variables are described as mean with standard deviation. Categorical variables are described as frequencies and proportions. Chisquare test was used to compare categorical data. Student's t-test was used to compare continuous variables. Statistics were considered statistically significant for $\mathrm{p}<0.05$.

\section{RESULTS}

A total of 717 patients between the ages of 49 and 75 were seen over the course of the study with a mean (SD) age of $62.0(6.5)$ and 215 (30.0\%) female. As depicted in Figure 1, prior CRC screening was done in 608 patients (84.8\%) with 597 (83.2\%) undergoing colonoscopy within 10 years of the encounter, $10(1.4 \%)$ undergoing FIT within 1 year, and $1(0.1 \%)$ undergoing both. Of the 109 patients who had not undergone prior CRC screening, the reasons for not screening included 80 ( $73.4 \%$ of 109 patients and $11.2 \%$ of the entire cohort) who were not offered CRC screening services and 29 (26.6\% and $4.0 \%$ of the entire cohort) who declined screening.

A flow diagram (Figure 2) demonstrates how the patients were ultimately included in the study. Of the 109 patients with no prior screening, 18 were excluded due to a need for diagnostic 
colonoscopy and none were excluded due to a family history of CRC. An additional 13 patients did not have CRC screening addressed at the time of the clinic encounter. This resulted in 78 patients without prior CRC screening who were included in the study.

Table 1 demonstrates baseline characteristics of 717 patients seen in clinic. Patients who received prior CRC screening compared to no prior screening were older (mean age $62.3 \pm 6.4$ vs $60.3 \pm 6.8, \mathrm{p}=0.003)$. A greater proportion of males compared to females had prior screening (86.9\% vs $80 \%, p=0.019)$. A greater proportion of White compared to Black patients had prior screening $(88.6 \%$ vs $78.3 \%, \mathrm{p}=0.027)$. A greater proportion of Veterans patients compared to County patients had prior screening $(90.8 \%$ vs $77.5 \%, \mathrm{p}<0.001)$. Collection periods 1 , 2 , and 3 had similar proportions of patients with prior screening $(84.7 \%, 85.6 \%$, vs $83.7 \%, \mathrm{p}=0.836)$, suggesting that the population across these three periods were similar.

Of the 78 included patients without prior screening, $56(71.8 \%)$ agreed to undergo screening including colonoscopy in 32 and FIT in 24. Tables 2 and 3 demonstrate characteristics of patients who did not receive prior CRC screening. Table 2 compares patients who agreed to undergo screening to patients who declined screening. Age $(60.3 \pm 5.9$ vs $60.6 \pm 9.1, \mathrm{p}=0.883)$ was similar between both groups. The proportion of males agreeing to undergo screening vs females was greater, although this approached but did not reach statistical significance $(79.2 \%$ vs $60 \%$, $\mathrm{p}=0.067$ ). The proportion of White patients agreeing to undergo screening was similar to Black patients $(51.0 \%$ vs $78.6 \%, \mathrm{p}=0.187)$. Patients who were not previously offered screening agreed to undergo screening $75 \%(39 / 52)$ of the time. The proportion of patients that agreed to undergo CRC screening, who were not previously offered screening was similar to those who were 
previously offered screening but declined ( $75 \%$ vs $65.4 \%, \mathrm{p}=0.374)$. The proportion of patients at the county hospital clinic agreeing to undergo screening was similar to patients at the VA clinic $(69.5 \%$ vs $78.9 \%, p=0.426)$. Patients seen by fellows in their $3^{\text {rd }}$ year of training agreed to undergo screening more often than fellows in their $1^{\text {st }}$ or $2^{\text {nd }}$ years of training $(100 \%$ vs $70.3 \%$ or $60.7 \%, \mathrm{p}=0.033$ ). There were similar proportions of patients seen during collection period 1,2 , or 3 that agreed to undergo screening ( $75 \%$ vs $73.5 \%$ vs $66.7 \%, \mathrm{p}=0.793)$.

Table 3 compares patients who agreed to undergo screening via colonoscopy to patients who agreed to undergo screening via FIT. Age $(60.3 \pm 6.2$ vs $60.4 \pm 5.5, \mathrm{p}=0.933)$ was similar between both groups. None of the following characteristics predict a choice of colonoscopy or FIT: gender (male $63.2 \%$ vs female $44.4 \%, \mathrm{p}=0.186$ ), race (White $52 \%$ vs Black $63.6 \%$, $\mathrm{p}=0.351$ ), reason for not previously undergoing screening (not offered $56.4 \%$ vs declined $58.8 \%$, $\mathrm{p}=0.867$ ), clinic location (county $61 \%$ vs VA $46.7 \%, \mathrm{p}=0.338$ ), fellow level of training $\left(1^{\text {st }}\right.$ year $57.7 \%$ vs $2^{\text {nd }}$ year $47.1 \%$ vs $3^{\text {rd }}$ year $\left.69.2 \%, p=0.476\right)$, or collection period $\left(1^{\text {st }}\right.$ period $46.7 \%$ vs $2^{\text {nd }}$ period $56 \%$ vs $3^{\text {rd }}$ period $\left.68.8 \%, p=0.457\right)$.

Finally, when comparing patients who had screening prior to being seen in the gastroenterology clinic to patients who agreed to undergo screening after being seen, a greater proportion of patients who had been screened previously used colonoscopy as their first screen modality as opposed to FIT (597/608 (98.2\%) vs 32/56 (57.1\%), p<0.001).

\section{LIMITATIONS}


There are several limitations to this study. This study is not generalizable to all patients since patients were seen at a local county hospital and a Veterans Administration Medical Center. Nevertheless, it was important to include the county hospital in this quality improvement initiative since this population of patients is underserved. Secondly, the study is not generalizable to all providers since the physicians offering colorectal cancer screening were all gastroenterology fellows. The lower rate of colorectal cancer screening in patients seen by less experienced fellows may have decreased the magnitude of effect of this study. On the other hand, gastroenterologists may have more experience discussing details about FIT or colonoscopy than general practitioners. Thirdly, the lack of difference seen in patients who underwent screening with FIT compared to colonoscopy is likely due to the study being underpowered to detect such differences. A larger study looking at all patient populations across several different types of practices and subspecialties should be done to address these limitations. Lastly, there may be referral bias since patients were seen at a gastroenterology clinic rather than a primary care clinic. We attempted to reduce this bias by excluding patients who were seen for symptoms that might be related to colonic disease that necessitated a diagnostic colonoscopy.

\section{DISCUSSION}

This study showed an $84.8 \%$ rate of colorectal cancer screening in a population of 717 patients between the ages of 49 and 75 referred to a gastroenterology fellow's clinic. This is better than 2013 national data demonstrating $61.2 \%$ of adults between the ages of 50 and 75 that were up-todate with CRC screening. ${ }^{10}$ This may reflect a referral bias as patients who come to clinic are more likely to be compliant with health care utilization. This also may reflect improvement in health care access since the Affordable Care Act was passed. Colonoscopy still remains the 
screening modality of choice, as an overwhelming majority (98.2\%) of patients who were screened, received colonoscopy.

A significant percent of patients (11.2\%) reported that they were never offered CRC screening. This number is concerning as these patients are typically referred to the gastroenterology clinic from their primary care physician, who should be the first line of providers referring patients for screening as well. This percent is also reflected in the 13 of $109(11.9 \%)$ patients who missed an opportunity for CRC screening despite being seen in a gastroenterology clinic. This suggests that we all need to do better to ensure all patients seen in our clinics are given recommendations to undergo CRC screening.

The baseline characteristics of patients who had undergone screening prior to being seen in the gastroenterology clinic show similar trends that are available nationally. Black patients ${ }^{11}$ and underserved populations ${ }^{12}$ (such as those seen at the county hospital clinic) are known to have lower rates of receiving CRC screening services, similar to this study. Older patients also tend to be screened more frequently in this data, which is not surprising since they had more eligible years of colorectal cancer screening and therefore more opportunity to undergo screening. Men also were more likely to be screened than women. It is unclear if this is a function of the populations in this study, as the Veterans population tends to be predominantly male and this is the population that is also more likely to undergo screening.

Although several differences were noted in the baseline group of patients referred to the gastroenterology clinic, these differences were not seen in the intervention group of patients who 
had not received prior colorectal screening. Patients in this study had systematic discussions about colorectal cancer screening. Age, comorbidity score, gender, race, and the county or VA clinic did not demonstrate discrepancies between patients who decided to undergo screening and patients who declined screening after these discussions. Although these factors, most notably race and socio-economic status, seem to play a role in the population as a whole, when physicians take the time to discuss colorectal cancer screening with patients, these factors become less important.

In this study, men agreed to undergo colorectal screening more frequently than women, as this approached but did not reach statistical significance. It is unclear why women tended to decline CRC screening at higher rates. However, the consequence of this is likely attenuated as men have been previously shown to have a higher risk of advanced adenomas during screening colonoscopies. $^{13,14}$

One important observation is that $75 \%$ of patients who previously declined CRC screening agreed to undergo screening after being seen by a gastroenterology fellow. This study demonstrates that a systematic approach to offering both colonoscopy and FIT can change patient's minds about screening. A prior randomized controlled trial comparing patients who were offered colonoscopy to patients who were offered either colonoscopy or fecal occult blood testing (FOBT) demonstrated that offering both colonoscopy and non-invasive testing improves screening rates. ${ }^{15}$ Although physicians feel more comfortable recommending colonoscopy ${ }^{9}$ a better job needs to be done in discussing non-invasive alternative options to improve rates of CRC screening. 
This study demonstrated that patients seen by $3^{\text {rd }}$ year fellows have higher rates of undergoing CRC screening compared to patients seen by $2^{\text {nd }}$ year and $1^{\text {st }}$ year fellows. This suggests that having a discussion with more experienced gastroenterologists can further improve rates of CRC screening. It is unclear whether this improvement is due to more years of training overall, or specifically more years of training in the field of gastroenterology. A study looking at rates of CRC screening in patients who have undergone discussions with either experienced internists or experienced gastroenterologists may answer this question. Furthermore, a larger study that includes more fellows from multiple institutions would need to be done to confirm these findings.

There were no differences in the characteristics of patients who agreed to undergo screening via colonoscopy compared to patients who agreed to undergo screening via FIT after a discussion in GI clinic. A larger study is likely needed to detect differences. Additionally, focus groups assessing the attitude of patients around the screening modalities may shed light on this topic. However, patients who had been screened previously were more likely to be screened by colonoscopy rather than FIT when compared to patients who agreed to undergo screening after a systematic discussion about both options. Although we were not able to study this directly, we suspect this difference is because patients only had colonoscopy previously offered to them. To improve Healthcare Effectiveness Data and Information Set (HEDIS) measures in primary care providers' clinics, we recommend that they be comfortable discussing alternative screening modalities with patients if colonoscopy is declined. 


\section{CONCLUSIONS}

This study demonstrated that $15 \%$ of eligible patients referred to a gastroenterology clinic had not previously undergone colorectal cancer screening. Older age, male gender, White race, and higher socioeconomic class is associated with higher rates of screening. However, when patients have systematic discussions about colonoscopy and FIT testing with a gastroenterology fellow, these differences are not seen. Discussions with a more experienced gastroenterology fellow may improve overall rates of screening.

\section{IMPLICATIONS}

Systematic discussions about both colonoscopy and the non-invasive FIT option likely improve overall rates of screening and may increase rates of utilizing FIT testing relative to colonoscopy for colorectal cancer screening. Further study is needed to see if these discussions will improve rates of colorectal cancer screening in additional populations. 
Figure 1. Prior CRC screening in patients referred to GI clinic. 
Figure 2. Flow diagram of patients included in the study. 


\section{References}

1. Edwards BK, Ward E, Kohler BA, et al. Annual report to the nation on the status of cancer, 19752006, featuring colorectal cancer trends and impact of interventions (risk factors, screening, and treatment) to reduce future rates. Cancer 2010;116:544-73.

2. Siegel R, Naishadham D, Jemal A. Cancer statistics, 2013. CA Cancer J Clin 2013;63:11-30.

3. Corley DA, Jensen CD, Marks AR, et al. Adenoma detection rate and risk of colorectal cancer and death. N Engl J Med 2014;370:1298-306.

4. Rex DK, Schoenfeld PS, Cohen J, et al. Quality indicators for colonoscopy. Gastrointest Endosc 2015;81:31-53.

5. Lee JK, Liles EG, Bent S, Levin TR, Corley DA. Accuracy of fecal immunochemical tests for colorectal cancer: systematic review and meta-analysis. Ann Intern Med 2014;160:171.

6. Levin B, Lieberman DA, McFarland B, et al. Screening and surveillance for the early detection of colorectal cancer and adenomatous polyps, 2008: a joint guideline from the American Cancer Society, the US Multi-Society Task Force on Colorectal Cancer, and the American College of Radiology. Gastroenterology 2008;134:1570-95.

7. Rex DK, Johnson DA, Anderson JC, et al. American College of Gastroenterology guidelines for colorectal cancer screening 2009 [corrected]. Am J Gastroenterol 2009;104:739-50.

8. Society. AC. Cancer prevention and early detection facts and figures 2010. American Cancer Society 2010.

9. McQueen A, Bartholomew LK, Greisinger AJ, et al. Behind closed doors: physician-patient discussions about colorectal cancer screening. J Gen Intern Med 2009;24:1228-35.

10. Fedewa SA, Goodman M, Flanders WD, et al. Elimination of cost-sharing and receipt of screening for colorectal and breast cancer. Cancer 2015;121:3272-80.

11. Laiyemo AO, Doubeni C, Pinsky PF, et al. Race and colorectal cancer disparities: health-care utilization vs different cancer susceptibilities. J Natl Cancer Inst 2010;102:538-46.

12. Wardle J, von Wagner C, Kralj-Hans I, et al. Effects of evidence-based strategies to reduce the socioeconomic gradient of uptake in the English NHS Bowel Cancer Screening Programme (ASCEND): four cluster-randomised controlled trials. Lancet 2016;387:751-9.

13. Ferlitsch M, Reinhart K, Pramhas $S$, et al. Sex-specific prevalence of adenomas, advanced adenomas, and colorectal cancer in individuals undergoing screening colonoscopy. JAMA 2011;306:1352-8.

14. Regula J, Rupinski M, Kraszewska E, et al. Colonoscopy in colorectal-cancer screening for detection of advanced neoplasia. N Engl J Med 2006;355:1863-72.

15. Inadomi JM, Vijan S, Janz NK, et al. Adherence to colorectal cancer screening: a randomized clinical trial of competing strategies. Arch Intern Med 2012;172:575-82. 


\section{Supplemental Digital Content}

Supplemental digital content \#1: Appendix - Physician guided discussion.docx 
Table 1. Baseline characteristics of 717 patients between the ages of 49 and 75 seen in GI clinic.

\begin{tabular}{|c|l|l|l|l|}
\hline & $\begin{array}{l}\text { Entire population } \\
(\mathrm{n}=717)\end{array}$ & $\begin{array}{l}\text { Prior screening } \\
(\mathrm{n}=608)\end{array}$ & $\begin{array}{l}\text { No prior screening } \\
(\mathrm{n}=109)\end{array}$ & -value \\
\hline Age, mean \pm SD & $62.0 \pm 6.5$ & $62.3 \pm 6.4$ & $60.3 \pm 6.8$ & 0.003 \\
\hline Charlson score & $2.0 \pm 1.5$ & $2.1 \pm 1.5$ & $1.7 \pm 1.3$ & 0.021 \\
\hline $\begin{array}{c}\text { Gender, } \mathrm{n}(\%) \\
\text { Female }\end{array}$ & $\begin{array}{l}215 / 717(30.0 \%) \\
\text { Male }\end{array}$ & $\begin{array}{l}172 / 717(80 \%) \\
502(70.0 \%)\end{array}$ & $\begin{array}{l}43(20 \%) \\
66(13.1 \%)\end{array}$ & 0.019 \\
\hline Race, $\mathrm{n}(\%)$ & & & & \\
White & $428 / 717(65.8 \%)$ & $379 / 428(88.6 \%)$ & $49(11.4 \%)$ & 0.027 \\
Black & $175(24.4 \%)$ & $137(78.3 \%)$ & $38(21.7 \%)$ & \\
Hispanic & $29(4.0 \%)$ & $25(86.2 \%)$ & $4(13.8 \%)$ & $1(25 \%)$ \\
Asian & $4(0.6 \%)$ & $3(75 \%)$ & $2(14.3 \%)$ & \\
Other & $14(2.0 \%)$ & $12(85.7 \%)$ & & $<0.001$ \\
\hline Population, $\mathrm{n}(\%)$ & & & $73(22.5 \%)$ & \\
County & $325 / 717(45.3 \%)$ & $252 / 325(77.5 \%)$ & $36(9.2 \%)$ & \\
Veterans & $392(54.7 \%)$ & $356(90.8 \%)$ & & \\
\hline Collection period & $216 / 717(30.1 \%)$ & $183 / 216(84.7 \%)$ & $33(15.3 \%)$ & \\
1 & $299(41.7 \%)$ & $256(85.6 \%)$ & $43(14.0 \%)$ & \\
2 & $202(28.2 \%)$ & $169(83.7 \%)$ & $33(16.3 \%)$ & \\
3 & & &
\end{tabular}


Table 2. Comparison of patients who agreed to undergo CRC screening vs those who declined screening.

\begin{tabular}{|c|c|c|c|}
\hline & $\begin{array}{l}\text { Agree to screen } \\
(\mathrm{n}=56)\end{array}$ & $\begin{array}{l}\text { Declined } \\
(\mathrm{n}=22)\end{array}$ & p-value \\
\hline Age, mean \pm SD & $60.3 \pm 5.9$ & $60.6 \pm 9.1$ & 0.883 \\
\hline Charlson score & $1.7 \pm 1.4$ & $2.1 \pm 1.3$ & 0.160 \\
\hline $\begin{array}{c}\text { Gender, } \mathrm{n}(\%) \\
\text { Female }(\mathrm{n}=30) \\
\text { Male }(\mathrm{n}=48)\end{array}$ & $\begin{array}{l}18 / 30(60 \%) \\
38(79.2 \%)\end{array}$ & $\begin{array}{l}12(40 \%) \\
10(20.8 \%)\end{array}$ & 0.067 \\
\hline $\begin{array}{c}\text { Race, } \mathrm{n}(\%) \\
\text { White }(\mathrm{n}=33) \\
\text { Black }(\mathrm{n}=28) \\
\text { Hispanic }(\mathrm{n}=3) \\
\text { Asian }(\mathrm{n}=1) \\
\text { Other }(\mathrm{n}=1)\end{array}$ & $\begin{array}{l}25 / 33(51.0 \%) \\
22(78.6 \%) \\
2(66.7 \%) \\
0 \\
0\end{array}$ & $\begin{array}{l}8(24.2 \%) \\
6(21.4 \%) \\
1(33.3 \%) \\
1 \\
1\end{array}$ & 0.187 \\
\hline $\begin{array}{l}\text { Reason not screened, } \mathrm{n}(\%) \\
\text { Not offered }(\mathrm{n}=52) \\
\text { Previously declined }(\mathrm{n}=26)\end{array}$ & $\begin{array}{l}39 / 52(75 \%) \\
17(65.4 \%)\end{array}$ & $\begin{array}{l}13(25 \%) \\
9(34.6 \%)\end{array}$ & 0.374 \\
\hline $\begin{array}{l}\text { Population, } \mathrm{n}(\%) \\
\text { County }(\mathrm{n}=59) \\
\text { Veterans }(\mathrm{n}=19)\end{array}$ & $\begin{array}{l}41 / 69(69.5 \%) \\
15(78.9 \%)\end{array}$ & $\begin{array}{l}18(30.5 \%) \\
4(21.1 \%)\end{array}$ & 0.426 \\
\hline $\begin{array}{c}\text { Fellow by year, } \mathrm{n}(\%) \\
1(\mathrm{n}=37) \\
2(\mathrm{n}=28) \\
3(\mathrm{n}=13)\end{array}$ & $\begin{array}{l}26 / 37(70.3 \%) \\
17(60.7 \%) \\
13(100 \%)\end{array}$ & $\begin{array}{l}11(29.7 \%) \\
11(39.3 \%) \\
0\end{array}$ & 0.033 \\
\hline $\begin{array}{c}\text { Collection period, } \mathrm{n}(\%) \\
1(\mathrm{n}=20) \\
2(\mathrm{n}=34) \\
3(\mathrm{n}=24)\end{array}$ & $\begin{array}{l}15 / 20(75 \%) \\
25(73.5 \%) \\
16(66.7 \%)\end{array}$ & $\begin{array}{l}5(25 \%) \\
9(26.5 \%) \\
8(33.3 \%)\end{array}$ & 0.793 \\
\hline
\end{tabular}


Table 3. Comparison of patients who agreed to undergo CRC screening with colonoscopy vs FIT.

\begin{tabular}{|c|c|c|c|}
\hline & \begin{tabular}{|l} 
Colonoscopy \\
$(\mathrm{n}=32)$
\end{tabular} & $\begin{array}{l}\text { FIT } \\
(\mathrm{n}=24)\end{array}$ & p-value \\
\hline Age, mean \pm SD & $60.3 \pm 6.2$ & $60.4 \pm 5.5$ & 0.933 \\
\hline Charlson score & $1.5 \pm 1.4$ & $1.8 \pm 1.2$ & 0.547 \\
\hline $\begin{array}{c}\text { Gender, } \mathrm{n}(\%) \\
\text { Female }(\mathrm{n}=18) \\
\text { Male }(\mathrm{n}=38)\end{array}$ & $\begin{array}{l}8 / 18(44.4 \%) \\
24 / 38(63.2 \%)\end{array}$ & $\begin{array}{l}10(55.6 \%) \\
14(36.8 \%)\end{array}$ & 0.186 \\
\hline $\begin{array}{l}\text { Race, } \mathrm{n}(\%) \\
\text { White }(\mathrm{n}=25) \\
\text { Black }(\mathrm{n}=22) \\
\text { Hispanic }(\mathrm{n}=2)\end{array}$ & $\begin{array}{l}13 / 25(52 \%) \\
14(63.6 \%) \\
2(100 \%)\end{array}$ & $\begin{array}{l}12 / 20(48 \%) \\
8(36.4 \%) \\
0\end{array}$ & 0.351 \\
\hline $\begin{array}{l}\text { Reason not screened, } \mathrm{n}(\%) \\
\text { Not offered }(\mathrm{n}=39) \\
\text { Previously declined }(\mathrm{n}=17)\end{array}$ & $\begin{array}{l}22 / 39(56.4 \%) \\
10(58.8 \%)\end{array}$ & $\begin{array}{l}17(43.6 \%) \\
7(41.2 \%)\end{array}$ & 0.867 \\
\hline $\begin{array}{l}\text { Population, } \mathrm{n}(\%) \\
\text { County }(\mathrm{n}=41) \\
\text { Veterans }(\mathrm{n}=15)\end{array}$ & $\begin{array}{l}25 / 41(61.0 \%) \\
7(46.7 \%)\end{array}$ & $\begin{array}{l}16(39.0 \%) \\
8(53.3 \%)\end{array}$ & 0.338 \\
\hline $\begin{array}{c}\text { Fellow by year, } \mathrm{n}(\%) \\
1(\mathrm{n}=26) \\
2(\mathrm{n}=17) \\
3(\mathrm{n}=13)\end{array}$ & $\begin{array}{l}15 / 26(57.7 \%) \\
8(47.1 \%) \\
9(69.2 \%)\end{array}$ & $\begin{array}{l}11(42.38 \%) \\
9(52.9 \%) \\
4(30.8 \%)\end{array}$ & 0.476 \\
\hline $\begin{array}{l}\text { Collection period, } \mathrm{n}(\%) \\
1(\mathrm{n}=15) \\
2(\mathrm{n}=25) \\
3(\mathrm{n}=16)\end{array}$ & $\begin{array}{l}7 / 15(46.7 \%) \\
14(56 \%) \\
11(68.8 \%)\end{array}$ & $\begin{array}{l}8(53.3 \%) \\
11(44 \%) \\
5(31.3 \%)\end{array}$ & 0.457 \\
\hline
\end{tabular}


No prior

screening,

Both, $1,0.1 \% \_109,15.2 \%$

FIT, $10,1.4 \%$

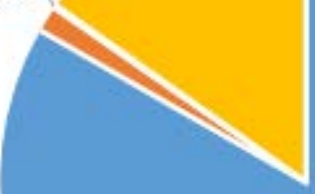

Colonoscopy,

$597,83.3 \%$ 
Assessed for eligibility $(n=717)$

Prior CRC screening ( $n=608)$

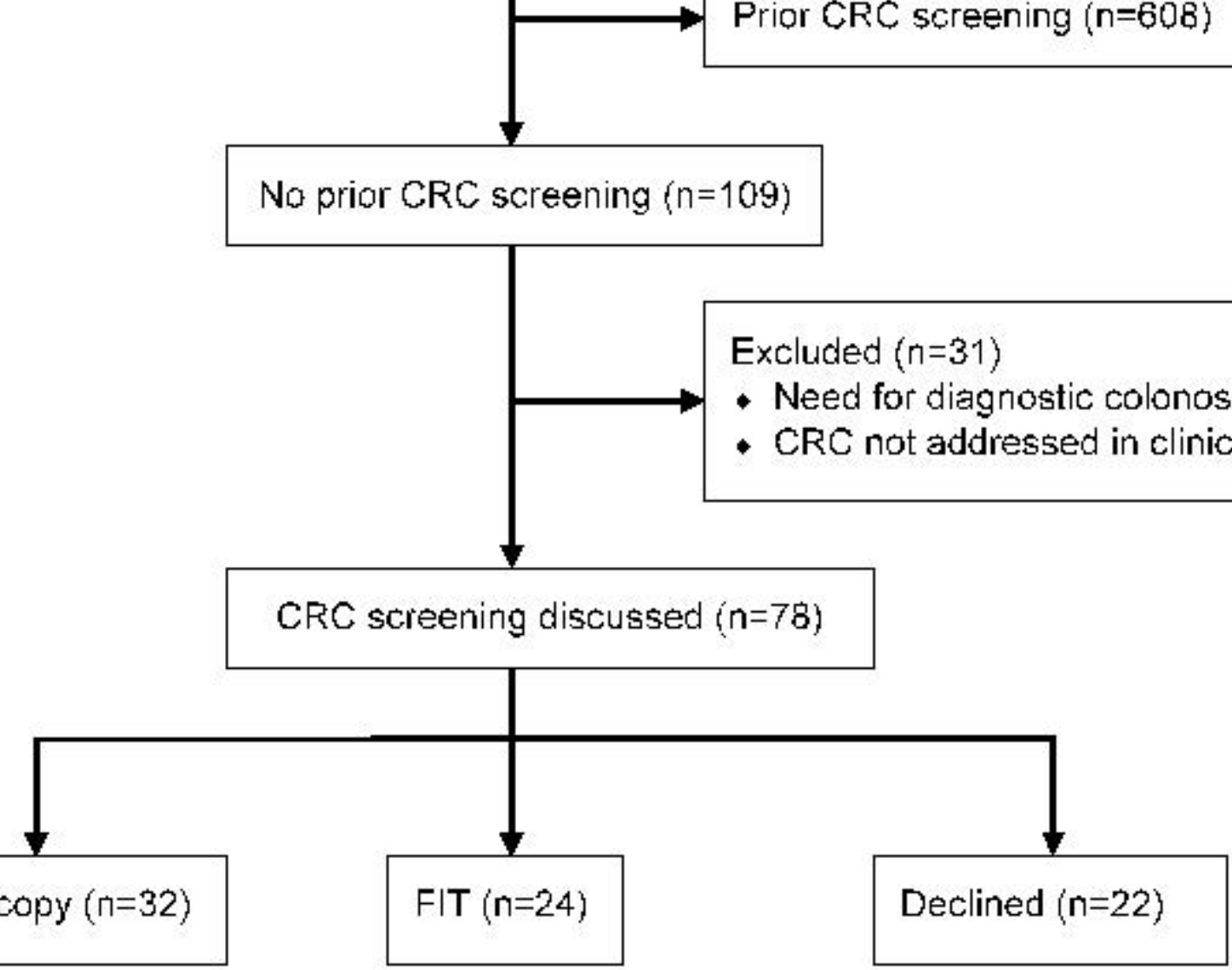

